\title{
Evaluation of the Effectiveness Computer-Assisted Language Teaching by Big Data Analysis
}

\author{
Honglei Wang, ${ }^{1}$ Yanjiao Du $\left(\mathbb{D},{ }^{2}\right.$ and Sang-Bing Tsai $\mathbb{D}^{3}$ \\ ${ }^{1}$ School of Japanese Studies, Xi'an International Studies University, Xi'an, Shaanxi 710128, China \\ ${ }^{2}$ School of Liberal Arts, Yanching Institute of Technology, Yancheng, He Bei 065201, China \\ ${ }^{3}$ Regional Green Economy Development Research Center, School of Business, WUYI University, Nanping, China
}

Correspondence should be addressed to Yanjiao Du; whlxisu@126.com

Received 28 September 2021; Revised 21 October 2021; Accepted 5 November 2021; Published 22 November 2021

Academic Editor: Chunlai Chai

Copyright (c) 2021 Honglei Wang et al. This is an open access article distributed under the Creative Commons Attribution License, which permits unrestricted use, distribution, and reproduction in any medium, provided the original work is properly cited.

This paper presents an in-depth study and evaluation analysis of the effects of the computer-assisted language teaching method on foreign language learning through its application. Using an empirical research approach, a practical study of computer-assisted English language teaching was conducted to verify the effects of CALL on oral language learning. In exploring the effects of CALL on students' oral learning, including the effects on fluency, accuracy, and complexity of oral expressions, as well as the effects on learning attitudes, CALL is conducive to improving the fluency of oral expressions, reducing the number of pauses and repetitions in oral expressions, and enabling students to consciously use articulation words to facilitate smooth expressions. CALL is good for improving the accuracy of students' speech, but it does not play a significant role in grammatical accuracy, and the grammatical errors are mainly in the third person singular of verbs, singular and plural of nouns, and passive voice. The use of CALL in teaching oral expressions does not improve the variety of sentences. However, the application of CALL in oral teaching stimulates students' enthusiasm for learning, improves their interest in learning spoken English, and increases their confidence in oral expression.

\section{Introduction}

Computer-assisted language learning (CALL) refers to the use of computer equipment, the Internet, and other computer-related tools for language learning. The application of CALL to English as a foreign language (EFL) and Electronic Sports League (ESL) is accepted and frequently used in the education industry. In addition, with the development and educational concept of progress, CALL has been taught all over the world [1]. And how to integrate new technology into English-speaking teaching to improve students' English-speaking expression ability is a problem that needs to be solved. Therefore, this study explores the impact of CALL on junior high school students' speaking learning by adopting CALL in English-speaking teaching, to provide useful insights for optimizing English-speaking teaching methods and building a reasonable speaking teaching model. In the environment of big data development, foreign language communicative ability is an indispensable factor for participating in social life [2]. Therefore, the cultivation of foreign language speaking ability has become the purpose of education, and with the attention of the educational community to the cultivation of English language ability, foreign language teaching has gradually become the focus of analysis and research discussions among experts and scholars [3]. Presence is a representative concept of virtual reality technology experience perception, but in the study of the technology acceptance model of virtual reality technology, there is a lack of in-depth analysis of the structure of presence; that is, the fact that presence is a complex, multifaceted psychological perception structure is ignored. The existing research on the adoption of virtual reality environments usually treats the sense of presence as an overall concept, without detailed research on the structure of the sense of presence, and the output results may lack accuracy and have insufficient reference value for the design of virtual reality environments. On the other hand, the sense of presence and 3I features are key features that can represent 
virtual reality technology, but there are few studies to explore the inner connection between the structure of sense of presence and 3I features. This study constructs a theoretical framework of virtual reality for foreign language speaking teaching to enrich the research results of the sense of presence theory and provide a more reference value of the receptive behavior model of the virtual reality environment [4].

Various stakeholders of education informatization policy, from the government to schools, from IT companies to international organizations and academic organizations, are actively involved in the development of education informatization. Specifically, government organizations play an important role in the top-level design of education informatization, contributing to policy guidance and continuous investment in education informatization. Based on the importance of education and the need to improve the quality and efficiency of education and reform the teaching system, government organizations promote education informatization projects by promulgating relevant regulations and establishing management bodies [5]. The government's leadership and management of education informatization are mainly through formulating, promulgating, implementing, and supervising the execution of education policies or regulations; allocating resources as rationally as possible; and properly handling the distribution of benefits to solve practical problems and promote the healthy and sustainable development of education informatization. Under the policy, countries will implement a series of action plans for education informatization and promote the implementation of the policy plan. International organizations grasp the direction of education informatization development from an overall international perspective and plan project implementation [6]. In the process of business, enterprises form a set of education informatization solutions that meet the development of education informatization of enterprises and also contribute to the development of education informatization of society; at the same time, enterprises also provide infrastructure and services for the development of education informatization, focus on long-term investment in the education market, and promote the sustainability of governmental organization policies and projects. The characteristic roots are all greater than 1 , and the cumulative explanation is 78.677 information, that is, most of the information contained in all variables can be effectively represented by these 5 factors. Academic organizations, on the other hand, stand at the forefront of the development of education informatization, promote research on education informatization, promote the in-depth application of education informatization, and promote the development of the theoretical level of education informatization to a higher level through theoretical research and promotion.

This study has certain theoretical investigation significance and practical value. From the theoretical point of view, the object of previous research on CALL is focused on college students, but this study focuses on junior high school students, a group of students in the middle stage of basic teaching, and probes deeply into the effects of CALL on junior high school students in terms of the complexity, accuracy, and fluency of oral expressions, which to a certain extent enriches the research group of CALL. From the practical level, the research on oral teaching of English in junior high school can, on the one hand, help English teachers pay attention to oral teaching, strengthen the cultivation of students' oral expression ability in the teaching process, and then reflect on the shortcomings of the current oral teaching mode and take the initiative to explore a new model of oral teaching; at the same time, they can constantly update their ideas of oral teaching and improve their teaching activities. At the same time, they will continue to update their teaching concepts, improve their teaching activities, and enrich their teaching skills to improve the quality of oral teaching and give full play to the characteristics of English as a subject. On the other hand, this study will help junior high school students discover the fun and practicality of learning spoken English and make them enjoy learning spoken English in the process of learning English; moreover, it will help junior high school students really realize the necessity of improving their oral expression ability, laying a solid foundation for the comprehensive and balanced development of students' future English ability, and truly reflecting the value of English class.

\section{Current Status of Research}

Oral language teaching is an important part of junior high school English teaching, and the improvement of junior high school students' English-speaking skills has an important impact on the improvement of other areas such as English reading, listening, and writing [7]. With the development of science and technology, the integration of education and technology has become inevitable, and English teachers are increasingly faced with the challenge of how to integrate new technologies into oral English teaching to improve students' English-speaking skills. With the development of CALL, computer-assisted language teaching has become a keen research area for scholars, and researchers at home and abroad have conducted increased researches in the field of computer-assisted speaking teaching [8]. The focus has been on the role and significance of computers, the Internet, and so on in facilitating language learning, which has been discussed more superficially, as well as exploring the impact of computer-assisted instruction on language learning [9]. Four major clusters of research were developed in this phase: negotiation of meaning, English as a foreign language, learner models, and speech blogs [10]. This phase developed research clusters focused on chat software, computers as a medium of communication, computer literacy, and teacher education. Much social software (e.g., voice chat software, blogs, and wikis) were widely used in CALL in this phase, thus posing higher demands on teachers and students' computer literacy and learning, as well as greater challenges for integrating CALL-related instructional design, making teacher computer education an important research direction [11].

In the deep application stage of CALL research, the main research directions are second language acquisition, collaborative learning, and data-driven learning. In this stage, 
the deep integration of technologies such as social networks, big data, learning management systems, and learning analytics makes mugshots (MOOCs), one of the important application modes of CALL, which provides support and assistance for learners to conduct online collaborative learning and independent learning and is widely used in foreign language teaching [12]. According to Kartal et al.'s research findings, future research hotspots will be mobile language learning, gamified language teaching and learning, and data-driven learning. How to integrate and apply these new technologies to enhance students' active, interesting, cooperative, and contextual language learning will be an important part of future research [13]. Again, technological advances in computer-assisted teaching have led to changes in the way language is taught and in the language learning environment, and this change has also led to a shift in the roles of teachers and students, which has placed new demands on teachers' teaching skills [14].

Therefore, how to train teachers to teach CALL and how to make better use of CALL to teach language, so that students' English knowledge, ability, efficacy, and selfconfidence can be improved, are the focus of future CALL research. Rienties et al. investigated how to measure fluency in speaking through Cool Edit Pro software [15]. An empirical study was used to demonstrate the effect of an intelligent software system with speech recognition technology on high school students' English speech facilitation. This calculation does not consider the long or short changes in the duration of each segment of the speech under different conditions, and the effect of speech recognition or speech comparison in this way is not good. The results of the study showed that a computer-aided pronunciation system based on automatic speech recognition technology combined with the traditional method of teacher explanation can improve the English speech of high school students more significantly. The English-speaking learning software installed on computers and cell phones has been favored by students because of its mobility and ease of operation and has also contributed to the improvement of students' oral expression skills to a certain extent and demonstrated its teaching effectiveness. This shows that in the research on softwareassisted English-speaking teaching, it is mostly a practical case and lacks a certain theoretical height and theoretical basis, which is the next direction to research softwareassisted speaking teaching.

\section{Evaluation Analysis of the Effectiveness of Computer-Assisted Language Teaching Method in Foreign Language Learning}

3.1. Overview of Computer-Assisted Language Teaching Methods. In the context of situational learning theory, the teaching of English as a foreign language means that students can fully understand the context in which the conversation takes place during daily oral training so that they can grasp the content of the spoken language in the context, rather than in the absence of the real situation. To meet this need, teachers are required to change their role from that of authority to that of a facilitator or learning partner of students. The computer system will provide students with more realistic contexts in which they can perceive the appropriate scenarios for oral expression, thus truly promoting students' oral communication skills [16]. Constructivism believes that students are the subjects of information processing and the constructors of cognitive structures, not the passive recipients of external stimuli. Constructivism believes that knowledge is not acquired by teachers but by learners through the construction of meaning with the help of other people (including teachers and learning partners) in a certain context, that is, social, and cultural background. The constructivist theory has changed the position of students and teachers in traditional teaching. In traditional teaching, the teacher is the focus [17]. Teachers have recognized CALL all over the world with the ability to read and write. At the same time, it pays more attention to the indepth curriculum reform. English teaching requires the comprehensive development of calligraphy students' listening skills. The teacher becomes the center of teaching, holds the dominant role, and plays the role of the transmitter and transporter of knowledge; the position of students and their subjective initiative in learning are not given enough attention, and they are often on the passive side. The constructivist theory emphasizes that teachers are the helpers and facilitators of meaning construction, not the transmitters and installers of knowledge and that students should be at the center, the subjects of cognition and the constructors of knowledge. It recognizes students' existing knowledge and experience and advocates that students give full play to their subjective initiative to process and internalize the old and new knowledge they learn so that they can take ownership of their learning. This is consistent with both the cognitive laws of human beings and the concept of advocating students to learn on their own, as shown in Figure 1.

Presence is a multidimensional structure, and the ideal questionnaire for presence should consider multidimensional structural properties and characterize it using a set of characteristics related to presence. There are both objective and subjective measures of presence, and the subjective measure is more widely used, for which Sheridan reasons that because presence is a mental performance, the basic measure should be self-report. Self-reported state measures can be very useful because quantifying a user's experience of presence allows statistical comparisons across media, stimuli, and subject groups. Presence is a relatively new concept and multidimensional construct for most nonexperts, so an understanding of presence should not directly ask respondents how they feel about being present. Researchers in different media contexts have developed appropriate presence measures and scales designed to elucidate the structure of presence, and these measures provide a reliable and valid dimension of measurement related to presence to optimize the teaching method of oral English in junior high school and construct a reasonable oral teaching model to provide beneficial enlightenment.

In general, scholars do not fully agree on the definition of the dimensions of English-speaking ability, but the common 


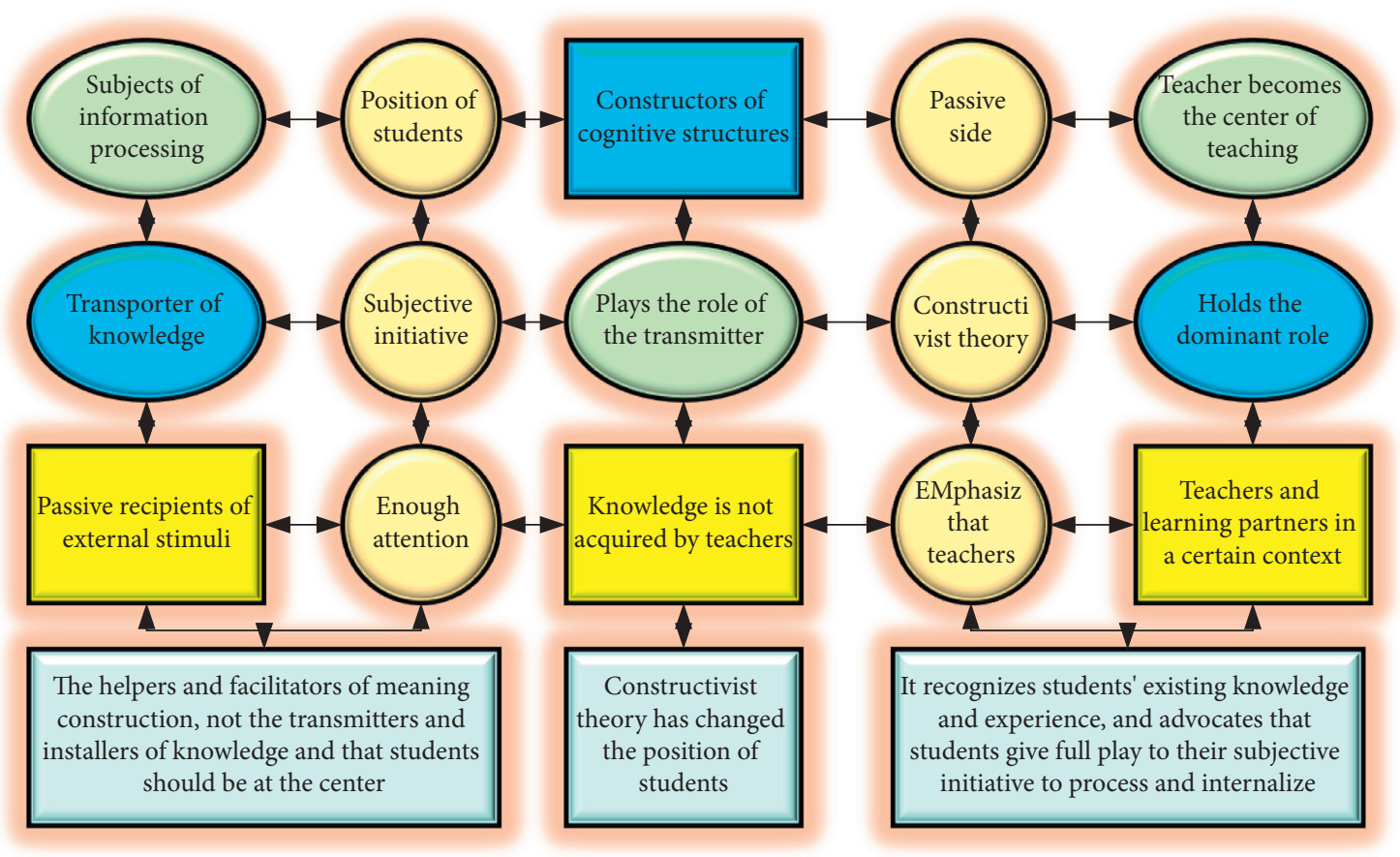

FIGURE 1: Framework of computer-assisted language teaching method.

factors involved in their evaluation indexes are language knowledge skills, language expression, communication ability, and discourse construction ability. Since the existing English speech ability scales are mainly designed for college students or graduate students, their specific item index descriptions are either too vague and abstract or too messy, lacking systematicity, and the scope of application for quantifying and evaluating English-speaking ability is somewhat limited. For high school English speech learners, the linguistic descriptions of specific items of Englishspeaking ability indicators should be clearer and more understandable, easy to understand briefly, and easy to operate.

In this study, two natural classes of the second year in a middle school in Weifang City were selected as the experimental class and the control class. The tests and surveys of the students in the two classes before the experiment revealed that the students in the two classes were relatively similar in terms of English-speaking level and learning attitude [18]. The main reasons for choosing the second-year students as the subjects of the study are: on the one hand, compared with the third-year students, the second-year students do not have the pressure of the midterm examination and have more class time for teaching oral English every week, which is convenient for the oral teaching study; on the other hand, the second-year students have accumulated a certain amount of vocabulary and English main grammar, which is suitable to be the experimental subjects of oral teaching. Both presence and characteristics are key features that can represent virtual reality technology, but few studies have explored the internal connection between presence structure and the three characteristics. To understand and count the speaking learning of students with different learning levels, the subjects were divided into three levels: high level, middle level, and low level according to the results of the pre-experimental test on students' speaking levels. Figure 2 shows the basic situation of the students in the experimental and control classes. Both the experimental and control classes took the pre-test and post-test of speaking, and only the students in the experimental class took all the accompanying tests. After the empirical teaching, the students in the experimental class took the questionnaire; in addition, the researcher selected nine students (three students each at high, medium, and low levels) from the experimental class as interviewees (see Figure 2).

This study was conducted to find teaching methods that could promote the improvement of secondary school students' oral expression. Four research methods, experimental method, text analysis method, questionnaire survey method, and interview method were used to compare and analyze the changes in students' oral expression ability and attitude toward oral expression before and after the experiment qualitatively and quantitatively to investigate the effectiveness of CALL in teaching oral English in junior high school. In terms of teaching environment, the experimental class taught in the school's multimedia computer classroom, where students each had a computer to learn speaking with the help of computer-assisted teaching equipment; the control class taught speaking in the ordinary teaching of daily learning. The computer-assisted teaching equipment used in the experimental class integrates computer technologies such as multimedia, hypertext, artificial intelligence, network communication, and knowledge base and has several functions such as human-computer dialogue, peer dialogue, teacher monitoring, simulated context, audio 


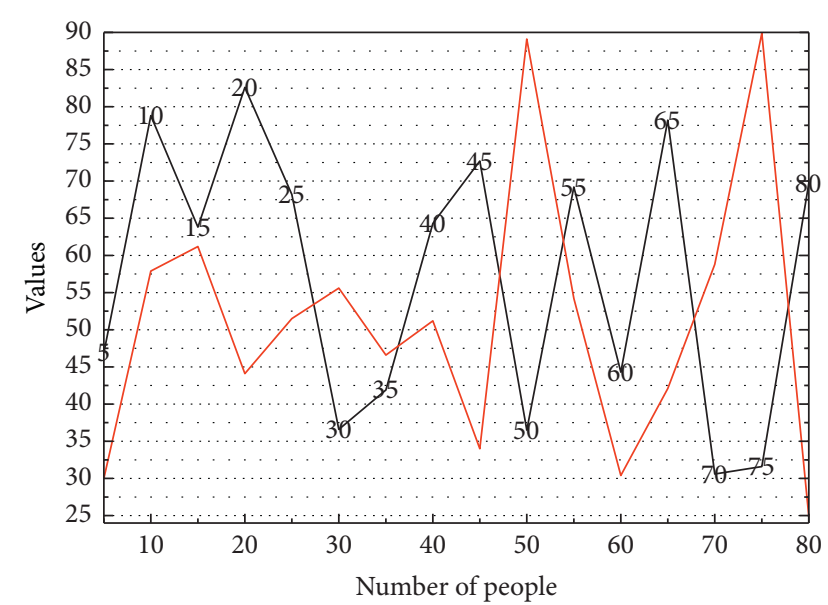

Figure 2: Basic information of students in the experimental and control classes.

playback, instant evaluation, and resource sharing. The four main functions used by teachers in the process of teaching are peer dialogue, simulated context, playback of recordings, and instant evaluation. It is understood that the schools in which this study is conducted, but teachers do not make high use of the machine-assisted teaching equipment and only use it for final tests or in the weeks before exams and for surprise training and rarely make use of the system in daily oral teaching.

In terms of teaching methods, CALL was adopted for the experimental class to teach speaking; the control class adopted the traditional teaching mode to teach speaking and used English class once a week to teach speaking according to the English teaching schedule, without a separate speaking class. Students in the experimental class took a test on the computer immediately after each class to test their classroom learning effect. Each student in the experimental class has a computer, and the teaching is conducted with the help of computers. The following is the way of teaching speaking in the experimental class. The distribution of benefits has to be handled properly to solve practical problems and promote the healthy and sustainable development of education informatization. The practice and research of English speech teaching based on college students mainly focus on their professional background, future needs, and speech contests, and the discussion of English speech teaching methods and contents are mostly limited to this, and the research perspective is not broad enough, while more relevant studies focus on the methods and strategies of English-speaking practice and teaching. Some researchers have used corpus technology to explore and study the use of pragmatic markers in English speech contests, analyzing their lexical features and discourse meaning and emphasizing the important role of pragmatic markers for speech expression and oral communication [19]. Other researchers have critically analyzed the citation of proverbs in English speeches in cross-cultural contexts, exploring the strategies and motives of British and American leaders in citing proverbs in cross-cultural contexts and the impact of the citation of proverbs on and motivations of British and
American leaders in citing proverbs in cross-cultural contexts and the important role of proverb citation on the function of speech.

3.2. Experimental Design for Assessing the Effectiveness of Applications in Foreign Language Learning. It refers to the degree to which the measurement tool or instrument can accurately measure the properties of the thing being measured and the degree to which the measurement result reflects the content of the target investigation. Validity analysis methods are divided into judgmental methods and empirical methods according to their types. From the perspective of the judgment method, solid theoretical support is the prerequisite for the robustness and completeness of the scale. The measurement dimensions and specific measurement items of this study have been referred to the credible scales and theories of the foreign and domestic clinical sense, and the dimensions have been confirmed and the items have been revised according to the characteristics of foreign language speaking context teaching, so they have high content validity. Next, the validity of the scale will be verified using the empirical method with small sample data.

The present validity analysis of the presence scale was conducted on 24 items of each dimension of the presence scale, which were retained after the previous reliability analysis [19]. In this study, principal component analysis was used to test whether the scale is suitable for factor analysis, and the statistical significance of the range of Kaiser-Meyer-Olkin (KMO) values is as follows: KMO test values greater than 0.9 indicate suitability for factor analysis, 0.8 to 0.9 indicates suitability for factor analysis, 0.7 to 0.8 indicates suitability for factor analysis, and 0.7 to 0.8 indicates suitability for factor analysis suitability for factor analysis. A test value less than 0.7 indicates unsuitability for factor analysis. Therefore, in this study, the KMO and Bartlett's sphere tests will be performed first before the principal component analysis. According to the test results in Figure 3, the KMO coefficient of the small sample is 0.935 , which is greater than the standard value of 0.7 , thus proving that it is suitable for factor analysis: The approximate chisquare value of Bartlett's sphere test is $4,045.332$, and the companion probability is 0.000 , which is less than 0.05 , and Bartlett's sphere test is significant, proving that it is suitable for factor analysis (see Figure 3).

Figure 3 analyzes the overall explained variance rate of the small sample data. From the total explained variance table in Figure 3, the virtual reality foreign language speaking teaching presence scale constructed in this study according to theoretical analysis and reliability test consists of five factors, which all have characteristic roots greater than 1 and cumulatively explain 78.677 interest, that is, most of the information contained in all variables can be effectively represented by these five factors of influence. To analyze the intrafactor aggregation and interfactor differentiation characteristics, next, the factor loadings of each variable were characterized with the help of the factor loading matrix, and the loading values represent the degree of influence of the 


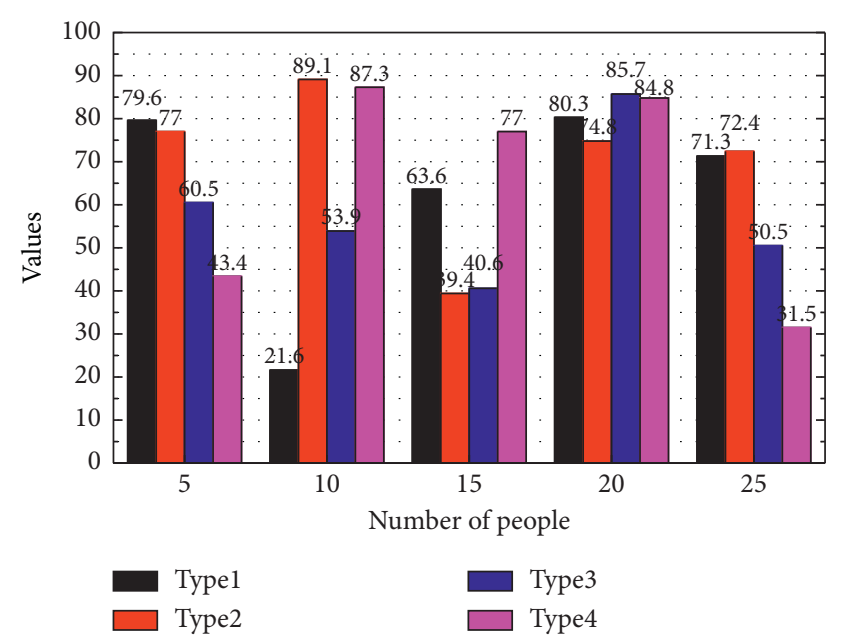

FIgURE 3: Small sample KMO and Barlett's sphere tests.

extracted principal component factors on the variables [20]. To a certain extent, it enriches the research group of CALL, and at the same time, it can provide certain reference data for the future research of oral English teaching in junior high school, and it can also provide useful theoretical guidance for the construction of oral English teaching mode in junior high school. Based on the principal component extraction above, the 24 influencing factors were further analyzed utilizing factor analysis. Five extracted principal component factors corresponded to each dimensional measure of proxemics predetermined in this study. The scale was optimized and validated through a small sample empirical study and reliability analysis.

The short-time over-zero rate refers to the number of times the short-time speech signal intersects the $x$-axis in one frame of time. The number of times the time-domain signal of a continuous speech signal passes the time axis is the over-zero rate, and the discrete signal with two sampling values of different signs means it passes the time axis once, from which the over-zero rate can be calculated. We define the short-time over-zero rate of the speech signal as follows:

$$
Z_{n}=\frac{1}{2}\left|\sum_{m=0}^{N-1} \operatorname{sgn}\left[x_{n}(m)\right]-\operatorname{sgn}\left[x_{n}(m+1)\right]\right| .
$$

The turbid tones with low energy frequency have a low over-zero rate, while the clear tones with high energy frequency have a relatively high over-zero rate. In general, we can find that speech segments have relatively stable overzero rates through the analysis of over-zero rates, white noise does not have this feature, so we can determine the endpoints of speech by short-time over-zero rates. Since the transformation of the signal in the time domain is usually difficult to see the characteristics of the signal, it is usually converted into the energy distribution in the frequency domain to observe the different energy distributions, which can represent the characteristics of different speech sounds. Therefore, after multiplying by the Hamming window, each frame must also undergo a fast Fourier transform to obtain the energy distribution on the frequency spectrum.

$$
\begin{aligned}
X(i, k) & =F F T\left(x_{i}(m+1)\right), \\
E(i, k) & =|X(i, k)|^{3}, \\
S(i, m) & =\sum_{k=0}^{N-1} E(i, k) H_{m}(k+1) .
\end{aligned}
$$

The HMM algorithm is complex and probability-based and requires a large amount of data application training and operations to obtain certain model parameters in the training phase. Although it is significantly better than the dynamic time regularization algorithm in the recognition of continuous speech, the difference between the two is not too obvious in the recognition of small vocabulary speech. Constructivism believes that students are the main body of information processing, the builder of cognitive structure, rather than the passive receiving and instilling objects of external stimuli. The DTW algorithm itself is both simple and effective and therefore has been widely used in specific situations. Dynamic temporal regularization is to make the reference template and test template different in time to achieve the best match by the dynamic planning principle, which is to bend two speech sequences with different times on the time axis so that the two speakers can be matched better. There are two-time sequences $M$ and $N$ with lengths $h$ and $k$, respectively, where the $M$ sequence is the reference template and the $N$ sequence is the test template, and the value of each point in the sequence is the feature value of each frame in the speech sequence. For example, the speech sequence $M$ has $h$ frames, and the feature value of the $i$-th frame is $m_{i}$.

$$
\begin{aligned}
& M=m_{1}, m_{2}, \ldots, m_{i}, \ldots, m_{h}, \\
& M=n_{1}, n_{2}, \ldots, n_{j}, \ldots, m_{k} .
\end{aligned}
$$

Now to compare the similarity of two speech time series, the above equation is the simplest one to calculate the distance between them if $h=k$. However, if $h$ is not equal to $k$, we need to align them. The simplest alignment is linear scaling, which means that the shorter sequence is linearly scaled to the same length as the longer sequence and then compared, or the longer sequence is linearly shortened to the same length as the shorter sequence and then compared. It has been proved that such calculation does not consider the fact that the duration of each segment in speech under different circumstances will produce longer or shorter changes, and speech recognition or speech comparison in this way is not effective, so the recognition effect is not likely to be optimal. A dynamic planning approach is more often used [21]. Given that the system does English phonetic recognition and the rest of the system functions consume a lot of resources, in the spirit of simplicity and easy computation, the DWT algorithm is used in this study to calculate the similarity between the test speech and the standard speech, as shown in Figure 4.

The valid scores obtained from the pre- and post-test were entered into SPSS 21.0 and analyzed by independent 


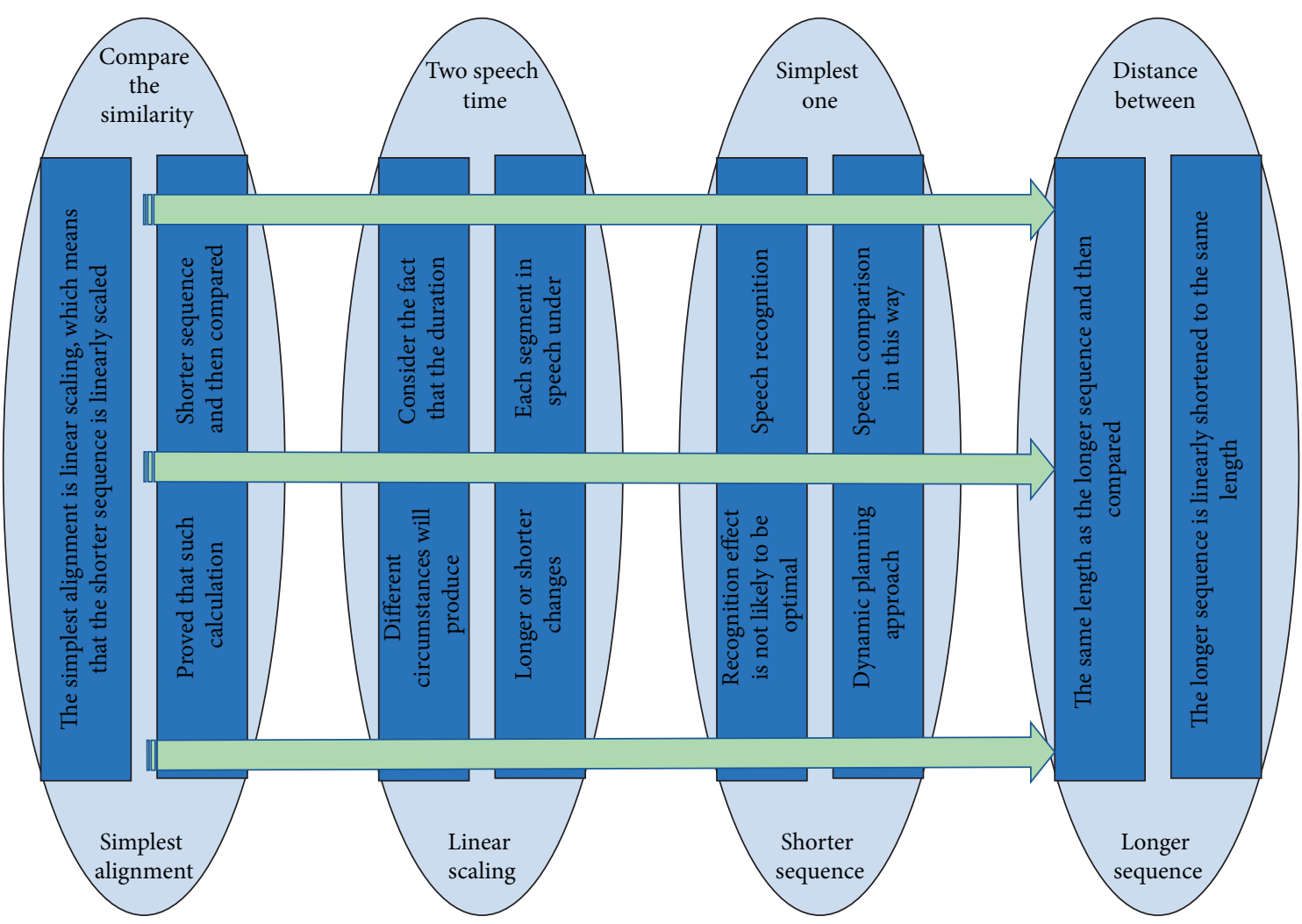

FIgURE 4: Experimental framework for application effect evaluation.

samples $t$-tests for total, fluency, accuracy, and complexity section scores of the two classes before, during, and after the experiment, with a $100 \%$ recall rate. A follow-up test was administered to the experimental class, and a stratified random sampling method was used to select six different students (two each at high, medium, and low levels) from the experimental class for each follow-up test, and their oral recordings were transcribed and analyzed. At the end of the experiment, questionnaires were distributed to the experimental class (45 students). Two invalid questionnaires were found after inspection, and the effective rate was $95.6 \%$. The obtained data were entered into SPSS 21.0 for data analysis, which included: reliability analysis of the questionnaire and descriptive statistical analysis of each question such as frequency and percentage.

\section{Analysis of Results}

4.1. The Effect of CALL on Students' Oral Expression. The study found that overall CALL had a positive effect on students' oral expressions. However, there were different effects on fluency, accuracy, and complexity of oral expressions, and the results of the study were as follows: CALL was beneficial in reducing the number of pauses and repetitions in students' oral expressions and in improving students' fluency. In terms of accuracy, CALL was beneficial in improving students' speech accuracy, but it did not play a significant role in grammatical accuracy. In terms of complexity, CALL is not conducive to the diversity of students' sentence use and does not contribute to the complexity of students' oral expressions, as shown in Figure 5. The effects

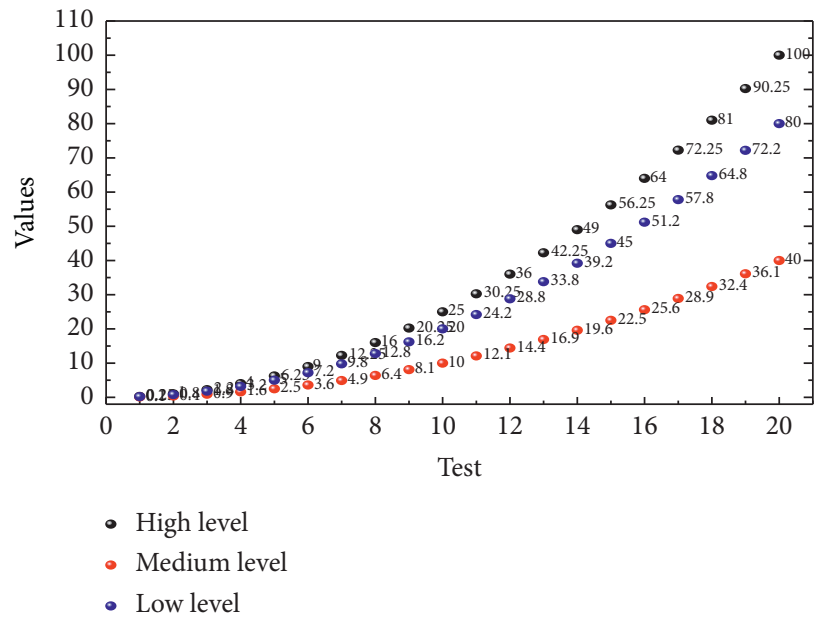

FIgURE 5: Changes in the number of pauses in the experimental class.

of CALL on students' oral learning will be discussed separately in the order of fluency, accuracy, and complexity, and then the positive effects of CALL on students' oral learning will be described. By comparing the performance analysis of oral fluency in the pre- and post-test, as well as the analysis of the recorded text of the follow-up test in the experimental class, we found that CALL was beneficial to the development of students' oral fluency in the following three aspects: (1) the analysis of the recorded text revealed that the number of pauses and repetitions of students' oral expressions in the 
experimental class were significantly reduced; (2) the number of pauses and repetitions of students' oral expressions in the experimental and control classes were significantly reduced in the post-test; and (3) in the independent samples $t$-test of the oral fluency scores of the experimental and control classes, a $P$ value of $0.024<0.05$ was obtained, and there was a significant difference in the oral fluency scores of the two classes (see Figure 5).

As can be seen from Figure 5, the number of pauses in the oral expressions of the high-, middle-, and low-level learners in the experimental class showed an overall decreasing trend, among which the decrease was the greatest for the low-level learners, with the maximum value of 11 and the minimum value of 5. This shows that CALL can effectively reduce the number of pauses in students' oral expressions. In Figure 5, the number of repetitions in oral expressions performed by the students in the experimental class showed an overall decreasing trend, indicating that CALL was beneficial in reducing the repetitions in the process of students' oral expressions. Compared with their text analysis, the number of pauses in the process of their oral expressions experienced the following changes. At first, the students would pause with Chinese intonation words such as "um, ah, then, oh no"; after a period of training, the students kept quiet when pausing and did not appear Chinese intonation auxiliaries; then they learned to use articulated conjunctions or phrases to replace silence. This article selects 40 English speeches by Chinese and American college students as the corpus. By analyzing the functions of pragmatic markers in the example and comparing the data information in the two sets of speeches, this article discovers several characteristics in the use of pragmatic markers by second language learners: (1) for the same type of pragmatic markers, China speakers tend to use monotonous vocabulary to express, while American speakers use multiple vocabularies to express; (2) Chinese speakers frequently use certain types of markers, while American speakers use multiple types of pragmatic markers; and (3) under the influence of cultural and educational background, Chinese speakers frequently use evaluation markers, while American speakers deliberately avoid using evaluation markers.

To compare the differences more precisely in oral fluency scores between the two classes after receiving different oral instruction, independent sample $t$-tests were conducted on the pre- and post-test scores of the two classes, and the results showed that the $P$ value was $0.024<0.05$ in the posttest, which proved that there was a significant difference between the oral fluency scores of the two classes, as shown in Figure 6.

As can be seen in Figure 6, in the pre-test of speaking, the experimental and control classes had relatively similar means in oral expression fluency, with a difference of 0.6 and means of 4.75 and 4.15 , respectively. $p$ (sig two-sided) after independent samples $t$-test was 0.149 , with a $p$-value greater than 0.05 , which did not reach the level of statistically significant difference. Therefore, before the empirical study, there was no significant difference in speaking fluency between the two classes. In the oral post-test, the mean values of oral fluency in the experimental and control classes were
5.75 and 4.775, respectively, with a difference of 0.975 . An independent samples $t$-test yielded a Sig value of 0.943 , which was greater than 0.05 , demonstrating that the variance of the two classes' scores on the post-test fluency was chisquare. A P (sig two-sided) of 0.024 , with a $P$-value less than 0.05 indicated that the experimental and the $p$-value is less than 0.05 , indicating that there is a significant difference between the post-test fluency scores of the experimental and control classes. This indicates that after a period of training, CALL is more advantageous than the traditional oral teaching method in terms of students' oral fluency.

Combining the analysis of the recordings of the speaking tests and the interviews with the students in the experimental class, the reasons for the higher fluency of the students in the experimental class are twofold: on the one hand, CALL provides students with contextualized speaking practice, which allows them to express themselves more generically, thus stimulating their thinking and desire to express themselves, making them more fluent and expressing a greater number of meaningful words. Students must have the opportunity to use language in meaningful contexts, as the context-based practice varies from context to context. On the other hand, CALL somewhat reduces students' fear of oral expression. From interviewing students, we know that many students are initially resistant to speaking English in public, probably due to shyness and fear of making mistakes. This may be due to shyness and fear of making mistakes. Practicing speaking in a CALL environment will avoid such a situation and make students dare to express themselves, which slowly builds up their self-confidence and thus their fluency in expressing themselves in any situation.

4.2. Application Effectiveness Evaluation Results. English speech learning and drills can enhance the core competence of English speech. Scholars' research objects are mainly college or graduate students, but the research object of this topic is the students taught by the author, high school students in the context of China's college entrance examination, whose language level, learning environment, and learning tasks are different from the characteristics of the existing related research objects. Therefore, understanding and grasping the basic information about the background, characteristics, and current situation of the research subject are important conditions to ensure that this study can achieve the expected results. In addition to some of the information already available, such as age, gender, and English language foundation, the author designed a questionnaire for them to gain a deeper understanding of their background and learning status related to their English learning. From Figure 7, we can see that the parents of the students in the experimental class are generally not well educated, with $80 \%$ of them having junior high school education or below, and only $5 \%$ of them having a college education or above, so it is difficult for them to guide and help their high school children in their studies, especially in foreign language subjects, which many parents know nothing about, and very few parents, less than $5 \%$, can give their children guidance in English learning. In other words, 


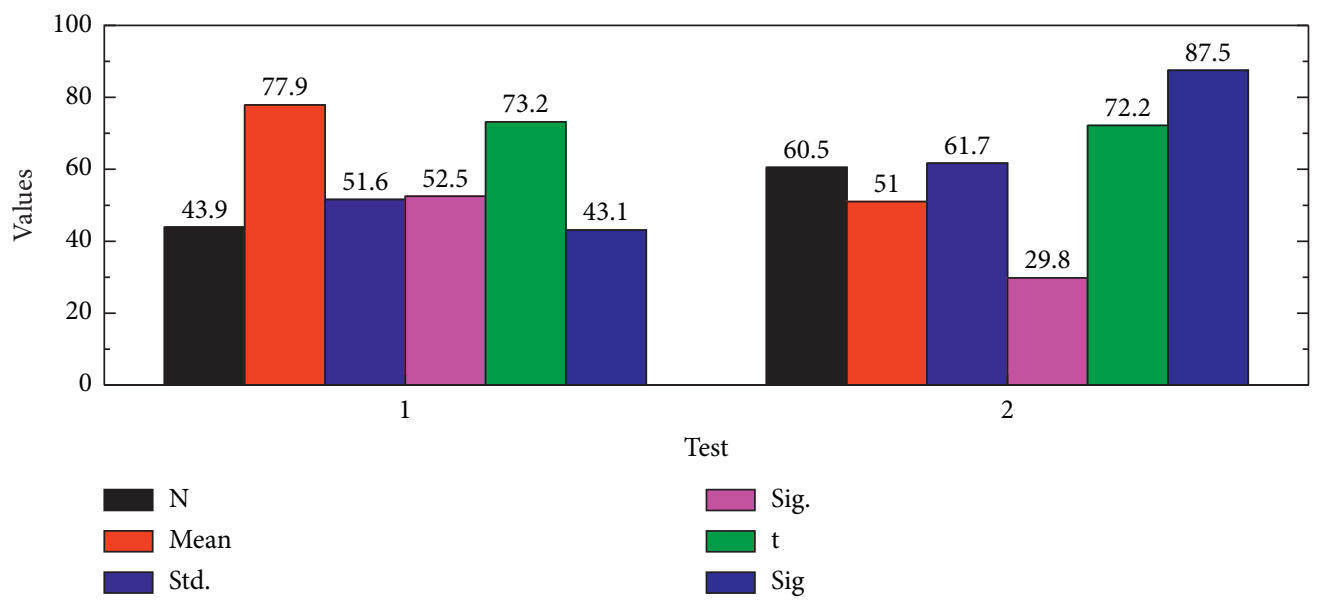

(a)

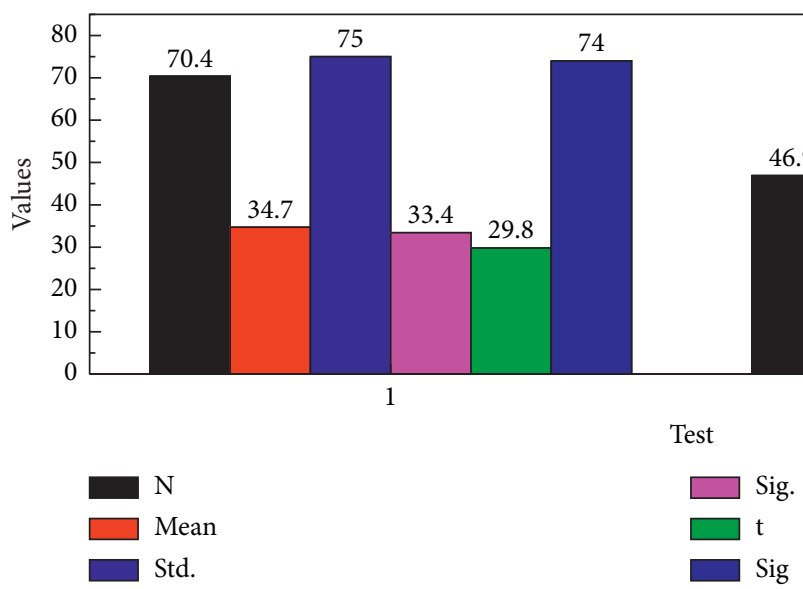

(b)

Figure 6: Independent sample $t$-test for fluency scores.

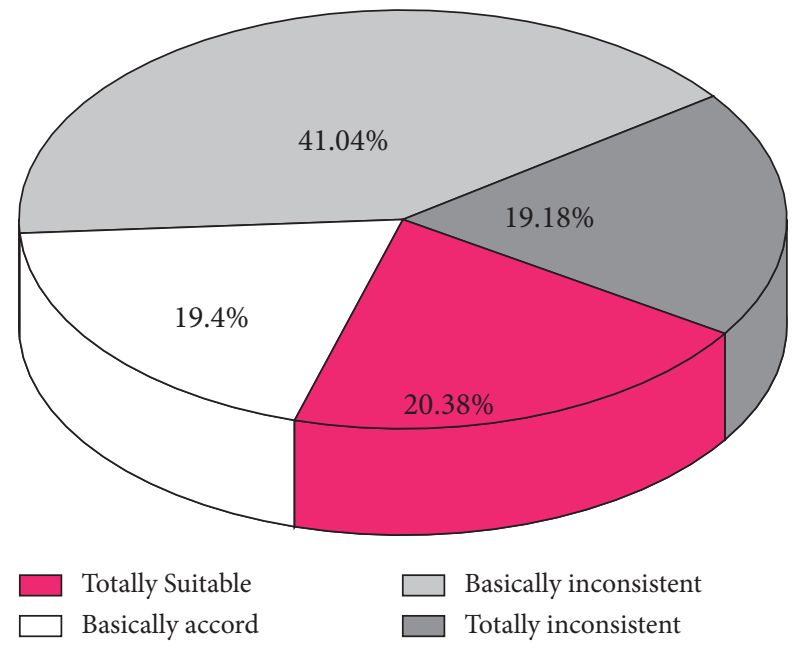

Figure 7: English learning information of students in the experimental class.

there is no significant positive or negative effect of family background on the English learning of the students in the experimental class (see Figure 7).
The differences in the sense of presence between male and female respondents were compared by an independent sample $t$-test, and the statistical comparison results are shown in Figure 7. The results show that: in the four aspects of immersion, interaction, authenticity, and social presence, the female respondents were significantly higher than the male respondents, confirming hypothesis 2 . The subjective measurement method is more widely used. In this regard, Sheridan's reason is that since presence is a psychological performance, the basic measurement method should be selfreport. The mean difference in immersion was 0.2277; the mean difference in interaction was 0.2514; the mean difference in interaction was 0.2824 ; and the difference in social presence was 0.2561 . This supports, to some extent, the study has verified that the difference in the effect of gender on social presence is not significant; this is partly related to the fact that the subject of the experimental study was a social presence in noninteractive television scenes, while the subject of this study is an immersive virtual reality system with more. This provides a new research context for analyzing gender differences in perceptions of presence. In the study, the difference in spatial presence perception between male and female research subjects was significant, and this 


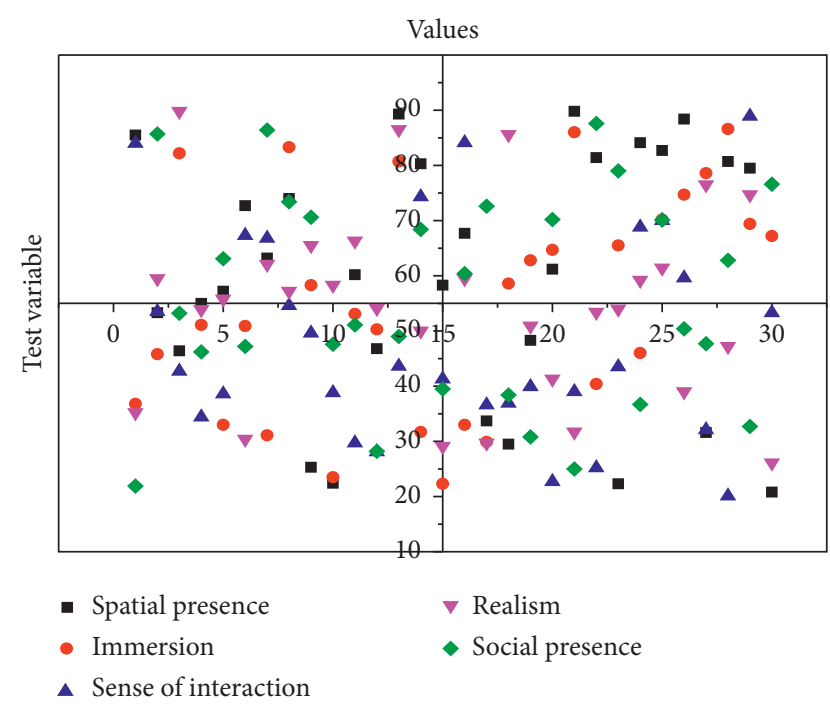

Figure 8: Comparison results of the difference in proximity.

finding is not consistent with the findings of this study, but considering that the virtual reality environment in this study was experienced by a video presentation, there is a difference in the degree of first-view perception and the way of experiencing the virtual reality situation in person, as shown in Figure 8.

CALL enhances the autonomy and personalization of students' learning. In the traditional speaking classroom, students can only follow the teacher's lecture, either memorizing the dialogues in the textbook or simply replacing them according to the dialogue patterns provided by the teacher, which restricts students' thinking in speaking learning. Teachers will provide different ways of practice for a certain topic, and students can choose according to their speaking level and interests, so they can take the autonomy of learning into their own hands, which greatly improves students' enthusiasm and initiative. This not only has a positive impact on the cultivation of students' autonomy in learning spoken English at this stage but also lays the foundation for students to develop good habits of independent learning in the future.

\section{Conclusion}

In this study, we learned from the analysis of the test results and the interviews with the study participants that the biggest obstacle for affecting students' oral expression is their lack of self-confidence. On the one hand, under the current environment of focusing on written test scores, students are used to listening to what teachers teach and neglecting their oral expression; thus students are unfamiliar and insecure about speaking English; on the other hand, students have a great psychological burden about speaking English in public because they are afraid of making mistakes and others' ridicule, which in the long run forms a vicious circle of not being able to speak, not daring to speak, and not being able to speak. After three months of oral study, we found that the students in the experimental class had experienced the process of speaking to the computer at the beginning, speaking with their peers, public speaking, and self-establishment. Computer-assisted teaching is compulsory for each student to express themselves orally so that students no longer feel unfamiliar with speaking English with a lot of practice. Because of the establishment of selfconfidence, students overcome their anxiety and fear when speaking and naturally make the whole expression more fluent and smoother, without the phenomenon of abnormal pauses and repeated reversals as in the early stage of oral teaching. This shows that the use of CALL in the Englishspeaking classroom has a positive impact on the students' self-confidence and fluency of oral expression.

\section{Data Availability}

The data used to support the findings of this study are included within the article.

\section{Conflicts of Interest}

No competing interests exist concerning this study.

\section{References}

[1] A. Bostancioğlu and Z. Handley, "Developing and validating a questionnaire for evaluating the EFL 'total PACKage': technological pedagogical content knowledge (TPACK) for English as a foreign language (EFL)," Computer Assisted Language Learning, vol. 31, no. 5-6, pp. 572-598, 2018.

[2] D. Tafazoli, M. E. Gómez-Parra, and C. A. Huertas-Abril, "A cross-cultural qualitative study on students' attitudes towards computer-assisted language learning," Qualitative Report, vol. 25, no. 7, pp. 1841-1855, 2020.

[3] K. Khoiriyah, "CALL and SLA theory: developing A framework to analyze web-based materials for teaching listening skills," Ideas: Journal on English Language Teaching and Learning, Linguistics and Literature, vol. 8, no. 1, pp. 80-92, 2020.

[4] H. Liu, C.-H. Lin, and D. Zhang, "Pedagogical beliefs and attitudes toward information and communication technology: a survey of teachers of English as a foreign language in China," Computer Assisted Language Learning, vol. 30, no. 8, pp. 745-765, 2017.

[5] C. Garcia, D. Nickolai, and L. Jones, "Traditional versus ASRbased pronunciation instruction an empirical study," Calico Journal, vol. 37, no. 3, pp. 213-232, 2020.

[6] R. Gangaiamaran and M. Pasupathi, "Review on use of mobile apps for language learning," International Journal of Applied Engineering Research, vol. 12, no. 21, pp. 11242-11251, 2017.

[7] T. Gonulal, "The use of Instagram as a mobile-assisted language learning tool," Contemporary Educational Technology, vol. 10, no. 3, pp. 309-323, 2019.

[8] P. Gruba and N. B. Chau Nguyen, "Evaluating technology integration in a Vietnamese university language program," Computer Assisted Language Learning, vol. 32, no. 5-6, pp. 619-637, 2019.

[9] S. Bibauw, T. François, and P. Desmet, "Discussing with a computer to practice a foreign language: research synthesis and conceptual framework of dialogue-based CALL," Computer Assisted Language Learning, vol. 32, no. 8, pp. 827-877, 2019. 
[10] N. Yigitcan Badem and F. Demiray Akbulut, "A general view on utilization of computational technologies in computer assisted language learning (CALL)," Education Reform Journal, vol. 4, no. 2, pp. 35-53, 2019.

[11] I. Irham, "Assessing livemocha and duolingo evaluation tasks: adapting chapelle call assessment criteria in autonomous leaning experience," Erudio Journal of Educational Innovation, vol. 5, no. 1, pp. 103-114, 2018.

[12] S. Loewen, D. Crowther, D. R. Isbell et al., "Mobile-assisted language learning: a Duolingo case study," ReCALL, vol. 31, no. 3, pp. 293-311, 2019.

[13] G. Kartal, "An analysis of using technology in language learning in three flagship journals," Mehmet Akif Ersoy Üniversitesi Eğitim Fakültesi Dergisi, no. 53, pp. 515-532, 2020.

[14] D. L. Rachmawati, D. Fadhilawati, and S. Setiawan, "The implementation of computer-assisted language learning (CALL) in the EFL setting: a case study in a secondary school in Indonesia," English Teaching Journal: A Journal of English Literature, Language and Education, vol. 8, no. 2, pp. 91-102, 2020.

[15] B. Rienties, T. Lewis, R. McFarlane, Q. Nguyen, and L. Toetenel, "Analytics in online and offline language learning environments: the role of learning design to understand student online engagement," Computer Assisted Language Learning, vol. 31, no. 3, pp. 273-293, 2018.

[16] L. De Paepe, "Student performance in online and face-to-face second language courses: Dutch L2 in adult education," Journal of Educational Sciences, vol. 37, no. 1, pp. 66-76, 2018.

[17] S. S. Tseng and H. C. Yeh, "Fostering EFL teachers' CALL competencies through project-based learning," Journal of Educational Technology \& Society, vol. 22, no. 1, pp. 94-105, 2019.

[18] S. Ruiz, P. Rebuschat, and D. Meurers, "The effects of working memory and declarative memory on instructed second language vocabulary learning: insights from intelligent CALL," Language Teaching Research, vol. 25, no. 4, pp. 510-539, 2021.

[19] B. A. Shawar, "Integrating CALL systems with chatbots as conversational partners," Computación Y Sistemas, vol. 21, no. 4, pp. 615-626, 2017.

[20] M. Alhamami, "Beliefs about and intention to learn a foreign language in face-to-face and online settings," Computer Assisted Language Learning, vol. 31, no. 1-2, pp. 90-113, 2018.

[21] E. Namaziandost, S. Alekasir, and S. A. Tilwani, "An account of EFL learners' vocabulary learning in a mobile-assisted language environment: the case of rosetta stone application," Computer Assisted Language Learning, vol. 22, no. 1, pp. 80-110. 